\title{
Vulnerability Assessment of West African Countries to Climate Change and Variability
}

\author{
Bobadoye Ayodotun ${ }^{1}$, Sylla Bamba ${ }^{2}$, Aderonke Adio ${ }^{1}$ \\ ${ }^{1}$ Forestry Research Institute of Nigeria (FRIN), Ibadan, Nigeria \\ ${ }^{2}$ West Africa Science Service Center on Climate Change and Adapted Land Use (WASCAL), Ouagadougou, Burkina-Faso \\ Email: bobadoyed@gmail.com
}

How to cite this paper: Ayodotun, B., Bamba, S., \& Adio, A. (2019). Vulnerability Assessment of West African Countries to Climate Change and Variability. Journal of Geoscience and Environment Protection, 7, 13-25.

https://doi.org/10.4236/gep.2019.76002

Received: December 13, 2018

Accepted: June 16, 2019

Published: June 19, 2019

Copyright (c) 2019 by author(s) and Scientific Research Publishing Inc. This work is licensed under the Creative Commons Attribution International License (CC BY 4.0).

http://creativecommons.org/licenses/by/4.0/

\begin{abstract}
This study was conducted to assess vulnerability of West African countries to climate change using selected indicators for adaptive capacity, exposure and sensitivity to generate vulnerability index for West African countries. Vulnerability index was calculated as the net effect of adaptive capacity, sensitivity and exposure to climate change. Principal Component Analysis (PCA) was used to assign weights to the vulnerability indicators used in this study. A total of thirteen (13) indicators were used to generate vulnerability index and vulnerability maps were produced using the GIS software package ArcGIS 10.2. The result shows that Niger, Mali and Mauritania have the highest levels of vulnerability to climate change in West Africa. The countries with the least levels of vulnerability to climate change are Ghana, Cape Verde and Gambia. Generally, this study shows that most countries in West Africa are vulnerable to climate change with ten countries (Niger, Mauritania, Mali, Burkina-Faso, Liberia, Senegal, Guinea Bissau, Guinea, Benin and Sierra Leone) having vulnerability levels higher than $50 \%$. We conclude that there is the need for well planned integrated adaptation measures to reduce the impact of climate change in the region.
\end{abstract}

\section{Keywords}

West Africa, Vulnerability Index, Climate Change

\section{Introduction}

The economy and livelihood of most countries in Africa, especially those of West Africa are driven by rain-fed agriculture and pastoralism. Food and Agricultural Organization (FAO) reported that agriculture alone provided jobs for almost $60 \%$ of the active labor forces; it accounted for 35\% of the Gross Domes- 
tic Product (GDP) and provided food supplies to $77 \%$ of the West African population (FAO, 2013). This accounts for why spatial and temporal variations in rainfall and drought episodes always have severe impact on the livelihood of people living in West Africa. Most West African countries lack the capacity to withstand drought and other extreme climatic events; this is due to limited capacity for disaster management, limited financial resources and weak institutional capacity in these countries (Rockstrom, 2008). In the West African region, the increase in the gap between population growth and agricultural capacity is exacerbating the already declining food security and increasing vulnerability.

Many studies have tried to analyze the concept and definition of vulnerability Chambers (1989), Downing (1991), Blaikie et al. (1994), Downing and Bakker (2000), Bobadoye (2016) and others. Most definitions of vulnerability contain a common thread. They all agree that vulnerability shows the degree of susceptibility of society to a hazard, which could vary either as a result of variable exposure to the hazard, or because of coping abilities. The intergovernmental panel for climate change (IPCC, 2014) defined vulnerability as "the degree to which a system (natural or social) is susceptible or unable to cope with the adverse effect of climate change and its extremes". It expressed vulnerability as a function of adaptive capacity (ability of the system to cope with or adjust to the changing context); sensitivity (ability of a system to be affected); and exposure (the incidence of events). Although, countries and regions may be exposed to the same climate change extremes, their adaptive capacity to climatic shock varies.

A large body of evidence has reported that exposure alone is not sufficient for understanding trends in disaster losses, and that social and economic vulnerabilities are critical ingredients (Mechler \& Bower, 2014; Cutter et al., 2003). West Africa has been identified as one of the regions that are most vulnerable to climate change both in terms of exposure to climate hazards (Turco et al., 2015) and social economic vulnerability (Acheampong et al., 2014). Tools such as spatial vulnerability mapping are useful for understanding patterns of vulnerability and risk of climate change at multiple scales and have been used by many researchers to analyse vulnerability to climate change (Midgley et al., 2008). The use of vulnerability maps among development agencies and governments is increasing as greater emphasis is placed on scientifically sound methods for targeting adaptation assistance (De Sherbinin et al., 2015). Mapping is useful because climate variability and extremes, the sensitivity of populations and systems to climatic stressors, and adaptive capacities are all spatially differentiated. The interplay of these factors produces different patterns of vulnerability. Typically, spatial vulnerability assessment involves data integration in which climate sensitivity and adaptive capacity data, including those derived from remote sensing, are combined with climate data to understand patterns of vulnerability and, in turn, inform where adaptation may be required. Maps have proven to be useful boundary objects in multi-stakeholder discussions, providing a common basis for discussion and for deliberations over adaptation planning. 
It is important to assess the level of vulnerability of regions and countries to climatic extremes for informed decision making, policy formulation and national planning. In this paper, the concept of vulnerability is expressed in a functional relationship with three key dimensions-exposure, sensitivity and adaptive capacity. Vulnerability relates to different degrees of exposure and sensitivity of a region or country to stress or stimuli, such as climate variability, and to a particular adaptive capacity of regions or country to cope with effects or risks associated with the exposure. The aim of this study is to analyse and map the vulnerability West African countries to climate change and variability.

\section{Methodology}

The integrated vulnerability assessment method was used to analyze the vulnerability of West African countries to climate change. Vulnerability is analyzed a function of the character, magnitude and rate of climate variation to which a system is exposed, its sensitivity and its adaptive capacity. When adaptive capacity of the system is less than the sensitivity and exposure, the system becomes more vulnerable to climate change impacts and the reverse is also true, the higher the adaptive capacity, the less vulnerable the system is to climate change impact. This method uses a combination of indicators to measure vulnerability by computing indices and weighted average for the selected indicators.

$$
V=\sum\left\{\left(A_{i} E_{i}+A_{i} S_{i}\right)-A_{i} C_{i}\right\} / N
$$

$V=$ Vulnerability of the countries to climate risks;

$E_{i}=$ Exposure of countries to climate risks;

$S_{i}=$ Sensitivity of countries to climate risks;

$C_{i}=$ Adaptive capacity of the countries to cope with climate risks and;

$N=$ Number of indicators used for the vulnerability analysis.

$A_{i}=$ First component score of each variable computed using PCA.

This approach is applicable at any scales (e.g. household, county/district, or regional level). The major limitation of the approach is that the selection of indicators and application of indices is subjective. However, the indicator approach is useful for monitoring trends and the composite indicators are able to capture the multi-dimensionality of vulnerability in a comprehensible form (Acheampong et al., 2014).

Principal component analysis (PCA) was used to assign weights to the indicators. Three common methods from the literature were used to assign weights to the indicators: 1) statistical methods, such as principal component analysis (PCA) or factor analysis (Cutter et al., 2003); 2) assigning equal weight to the indicators (O’Brien et al., 2004); and 3) Expert judgment (Brooks et al., 2005). Statistical method such as the PCA was deemed as the most unbiased approach. The resulting component scores and vulnerability index was rescaled so that they vary from 0 - 100. Results were presented using maps. The level of exposure, sensitivity and adaptive capacity of countries in West Africa were mapped using Arcgis 10.2. A vulnerability map of West Africa was also produced using 
Arcgis 10.3.

\section{Selection of Vulnerability Indicators for West Africa}

The indicators used for this study are presented in Table 1. Indicators were selected through literature surveys for the assessment of climate change vulnerability in sub Saharan Africa and also expert opinion. We identified a list of twelve (12) commonly used indicators of exposure, sensitivity and adaptive capacity in the region. We also used indicators from recent research that will be useful in analysing vulnerability in the region. The selection of indicators was based on three criteria 1) relevancy-theoretically well-founded within the vulnerability framework; 2) adequacy-accurately measures relevant data that identifies the direction of influence between the indicator and vulnerability; and 3) data availability - publicly available data for analysis. Indicators that have direct impact on the agricultural sector were mainly considered. This is due to the impact of climate change on agriculture in West Africa (IPCC, 2014), and also because of the dependency of majority of the population on subsistence rain fed agriculture in West Africa.

The indicators for climate exposure sought to measure average conditions as well as variation in precipitation, variation in Normalized Difference Vegetation Index and recorded extreme events. Gridded rainfall dataset from TAMSAT which presents a larger time cover with a wide spatial representation over West Africa, was used for the study. TAMSAT produces rainfall estimates for all of Africa at $4 \mathrm{~km}$ resolution. The TAMSAT archive spans 1983 to the delayed present. The longevity of the dataset makes it especially suitable for risk assessment. Applications of the data include famine early warning, drought insurance and agricultural decision support. This study used vegetation indices from the National Aeronautical and Space Administration (NASA) AVHRR NDVI, covering the period 1982-2013 with horizontal resolution of $8 \mathrm{~km}$. The Coefficient of Variation of Normalized Difference Vegetation Index (NDVI) indicator supplements the Interannual Coefficient of Variation in Precipitation. The percentage of the population exposed to drought, floods and extreme events provide information on the population that is affected by natural disaster. The population affected is the number of people injured, left homeless or requiring immediate assistance during a period of emergency resulting from a natural disaster; it can also include displaced or evacuated people. The average percentage of the population affected is calculated by dividing the sum of total affected for the period stated (1990-2009) by the sum of the annual population figures. The indicator was generated from the World Bank website.

Adaptive capacity in this study is defined as the ability of a country to cope with the impacts of climate change (particularly drought) and it is estimated by a set of proxy socioeconomic and agricultural based indicators Agricultural irrigated land refers to agricultural areas, purposely provided with water, including land irrigated by controlled flooding. Data on percentage Agricultural irrigated land was sourced from the FAO website. Irrigation and drainage continue to be 
an important source of productivity growth; especially in Sub-Saharan Africa that still have large untapped water resources for agriculture. Data on available arable land was also generated from the FAO website. Crop Production Index provides information on agricultural production for each year relative to the base period 2004-2006. It includes all crops except fodder crops. Regional and income group aggregates for the FAO's production indexes are calculated from the underlying values in international dollars, normalized to the base period 2004-2006. The Land Management Index (LMI) is a measure of governance potential to reduce land degradation based on actors' capacity, organisations' commitment and institutions' enabling environment for sustainable land management. The governance of land management emphasizes that sustainable land management is a co-product of sustainable management practices and collaborative management arrangements. The LMI was developed by The United Nations Convention to Combat Desertification in those countries experiencing serious Drought and/or Desertification (UNCCD) in 2017. Other adaptive capacity indicators used in this study are access to electricity and mobile phone subscription. These indicators enhance access to information and communication. These two indicators are very important, especially when you are dealing with agricultural based livelihood and also during natural disasters.

Sensitivity in this study is defined as indicators that influence the degree to which the countries are affected or response to climate change. The selected sensitivity indicators for this study are Human Development Index, Percentage of the population living below $\$ 3.20$ per day, literacy level and children under age

Table 1. Indicators used for vulnerability analysis.

\begin{tabular}{|c|c|c|}
\hline $\begin{array}{l}\text { Vulnerability } \\
\text { determinant }\end{array}$ & Indicators & Hypothesised functional relationship between indicator and vulnerability \\
\hline & Human development Index (HDI) & The higher the HDI the lower the vulnerability \\
\hline \multicolumn{3}{|l|}{ Sensitivity } \\
\hline & Population living under $\$ 3.20(\%)$ & The higher the number \% population living under $\$ 3.20$, the higher the vulnerability \\
\hline & Literacy level (\%) & The higher the literacy level the lower the vulnerability \\
\hline & $\begin{array}{l}\text { Children under age of } 5 \text { years } \\
\text { underweight }(\%)\end{array}$ & The higher the $\%$ of under age children underweight the higher the vulnerability \\
\hline \multirow[t]{5}{*}{ Adaptive capacity } & Irrigated arable land (\%) & The higher the percentage irrigated arable land, the lower the vulnerability \\
\hline & Land management index & The higher the land management index the lower the vulnerability \\
\hline & Crop production index & The higher the crop production index, the lower the vulnerability \\
\hline & Access to electricity (\%) & $\begin{array}{l}\text { The higher the percentage of population that have access to electricity the lower the } \\
\text { vulnerability }\end{array}$ \\
\hline & Mobile cellular subscription (\%) & The higher the \% cellular subscription the lower the vulnerability \\
\hline \multirow[t]{3}{*}{ Exposure } & $\begin{array}{l}\text { Population exposed to drought, floods } \\
\text { and extreme temp (\%) }\end{array}$ & The higher the population exposed to extreme events the higher the vulnerability \\
\hline & Coefficient of variation in precipitation & The higher the co efficient of variation of precipitation the higher the vulnerability \\
\hline & Coefficient of variation in NDVI & The higher the coefficient of variation of NDVI the higher the vulnerability \\
\hline
\end{tabular}


of 5 years that are underweight. Gbetibouo et al., (2010), reported that vulnerability to drought is influenced by financial, human, natural, physical and social capital assets. The human development index was created to emphasize that human beings and their capabilities should be the ultimate criteria for assessing the ultimate development of a country. HDI takes into consideration the life expectancy index, the education index and the Gross National Income (GNI) index. The higher the HDI of the country, the more likely the citizens are able to cope or adjust to external shock, environmental disasters and climate change. The data for sensitivity indicators used in this study was sourced from the world bank report 2017.

\section{Results and Discussion}

The result of the adaptive capacity of West African countries to climate change is presented in Figure 1. The map shows the average adaptive capacity of countries based on the indicator used in the research. Maps are a useful boundary object for generating discussions among stakeholders with different objectives and technical backgrounds, they can provide useful input for targeting development assistance. While national maps can be useful in discussion and decision making at the regional and national levels, Adaptation is mainly local and vulnerability at the

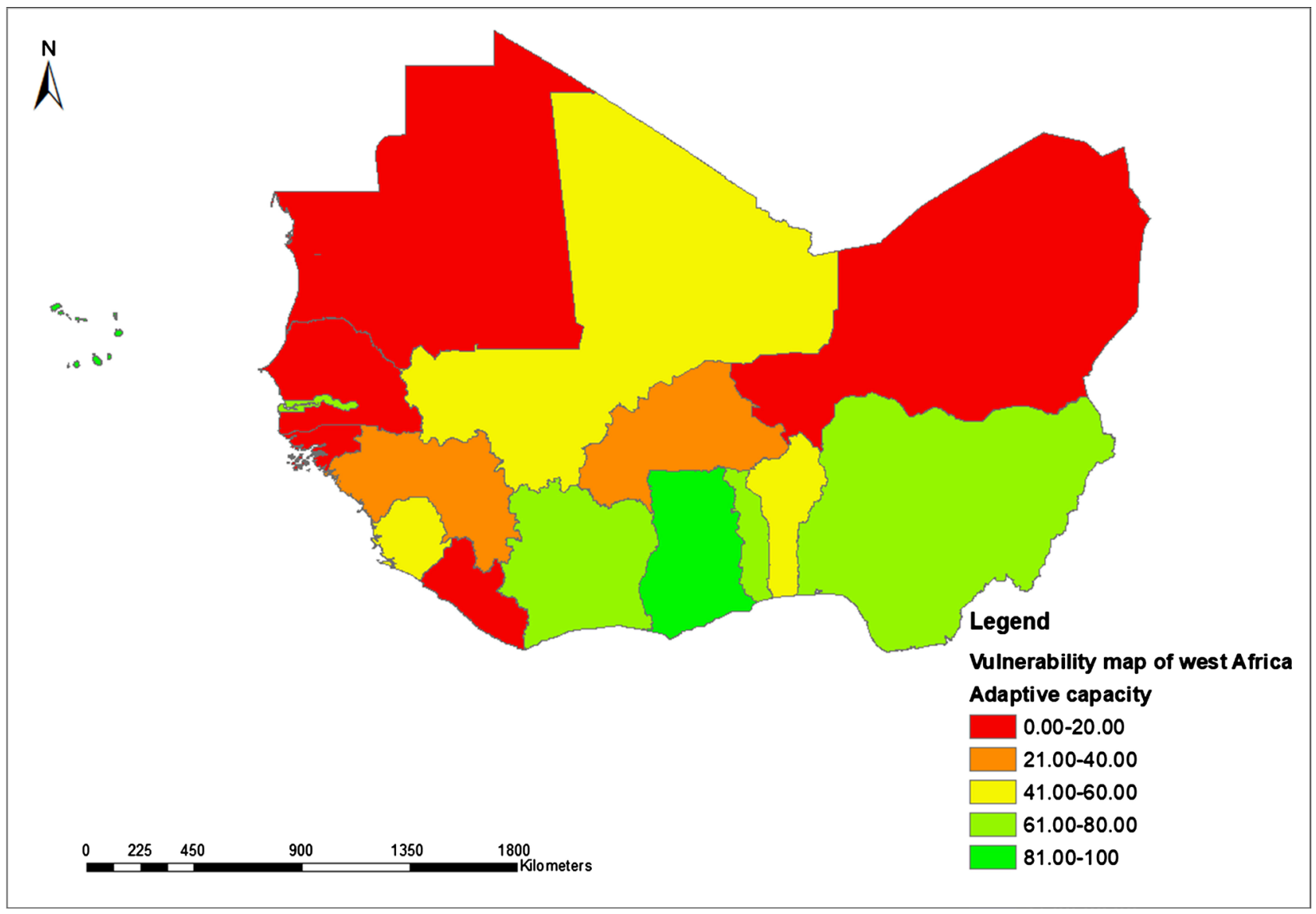

Figure 1. Map showing the adaptive capacity of West African countries to climate change. 
local and community levels should be taken into consideration when planning adaptation. The adaptive capacity result of the 16 West African countries shows that Cape Verde (73.03) had the highest adaptive capacity, followed by Ghana (61.45), Togo (47.51) and Nigeria (44.07) respectively. The countries with the least adaptive capacity are Liberia (17.32), Niger (22.88) and Mauritania (24.08). The result shows that the dry Sahel regions of West Africa, especially Niger and Mauritania have less adaptive capacity to climate change. Dry Sahel regions of West Africa are particularly prone to climate change and their adaptive capacity is low (Lebel \& Amani, 1999; De Sherbinin et al., 2015; Fiorillo et al., 2018). The agricultural sector was considered in selecting adaptive capacity indicators in this study. West African countries depend on rainfed agriculture, the low amount of rainfall in the Sahel region of West Africa, coupled with limited irrigation practice reduces the adaptive capacity and increase vulnerability of the Sahel countries to climate change and variability (Mortimore \& Adams, 2001; Muller et al, 2014; Turco et al., 2015). Research has shown that social, political and economic indices are important in analysing vulnerability to climate change (Cutter et al., 2003; Mechler \& Bouwer, 2014). The social and political challenges Liberia has experienced in the last three decades affected the adaptive capacity of the country to climate change. Liberia has been faced with years of civil war; this coupled with the recent Ebola crisis have severe effects on their ability to adapt to external shock. The coastal countries, Cape Verde, Ghana, Nigeria and Togo have higher adaptive capacity in this study. This can be attributed to higher rainfall in the region that supports the agricultural sector in these countries (Bamba et al., 2015). Generally, the adaptive capacities of West African countries to climate change are low. West Africa region has been reported as one of the regions that are most vulnerable to climate change (Cutter et al., 2003; De Sherbinin et al., 2015). The region is highly exposed to climate change related extremes and it has limited capacity and technical ability to cope with the predicted impacts of climate change and variability (Muller et al., 2014; IPCC, 2014; Turco et al., 2015). In this study, Only Cape Verde and Ghana have adaptive capacity, higher than $50 \%$. The other West African countries have adaptive capacity below the 50 percentile, with six countries (Guinea, Guinea Bissau, Liberia, Mauritania, Niger and Senegal) having adaptive capacity below $30 \%$. This confirms the low adaptive capacity of most countries in West Africa to climate change and variability.

The result on the level of exposure of African countries to climate change is presented in Figure 2. The exposure indicators used in this study are coefficient of variation of average annual precipitation, coefficient of variation of Normalized Difference Vegetation Index (NDVI), and percentage of Population exposed to drought, floods and extreme temperature. The result shows that the countries with the highest levels of exposure to climate change are Niger, Mauritania, Mali and Senegal. The study shows that most countries in the Sahel zone of the region have high levels of exposure to climate change. This can be attributed 


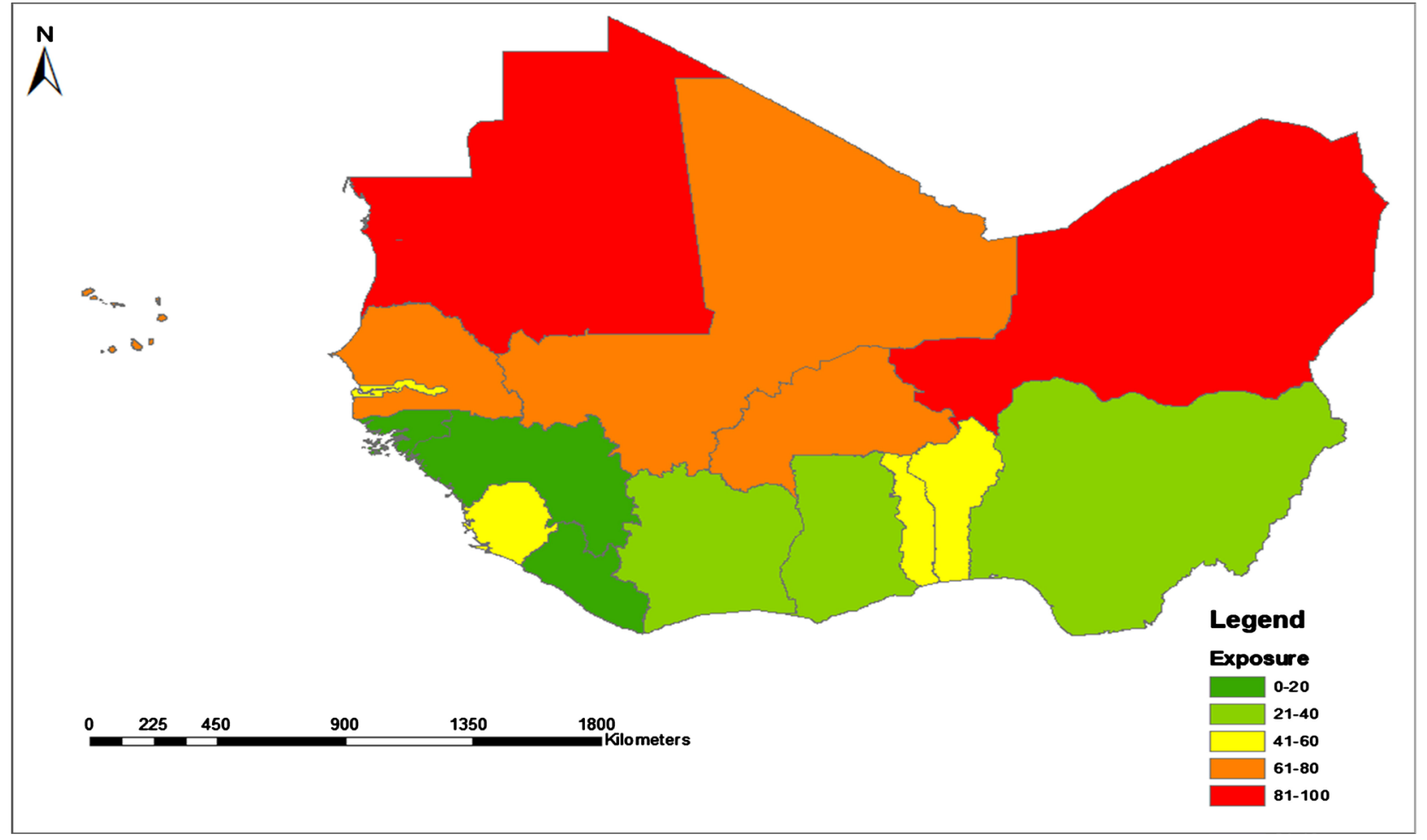

Figure 2. Map showing the levels of exposure of countries to climate change in West African countries.

to the low amount of rainfall and sparse vegetation cover in most part of these countries. Bamba et al., 2015 reported that the zones of vegetation in West Africa are principally related to rainfall-based climatic zones and the nature of the soil, with northern regions having increasingly drier vegetation upto the Sahara desert. Generally, in West Africa, countries with low amount of rainfall and increase drought occurrence are usually exposed to climate change and variability; this is due to the dependence of rainfall agriculture in the region (De Sherbinin et al., 2015).

The countries with the least levels of exposure to climate change are Guinea, Guinea Bissau, Liberia and Ghana. These countries are coastal countries that experience rainfall almost throughout the year and have highly dense tropical vegetative cover. Occurrence of drought event is not prominent in these countries and the agricultural sector is not as exposed to the impact of climate change when compared to countries in the Sahel region. Asare-Kyei (2017), reported that the frequency of occurrence of extreme events is expected to increase and the interaction of climate change with non-climate stressors will aggravate vulnerability of agricultural systems in the Sahel and Sudanian Savanna region of West Africa.

The report of sensitivity of West Africa countries to climate change (Figure 3) shows that Niger, Mali, Sierra Leone, Guinea and Burkina-Faso are highly sensitive to the climate change. The least sensitive countries are Ghana, Mauritania and Cape Verde. Sensitivity indicators are indicators that influence the degree to which the countries are affected or response to climate change. They are mainly 


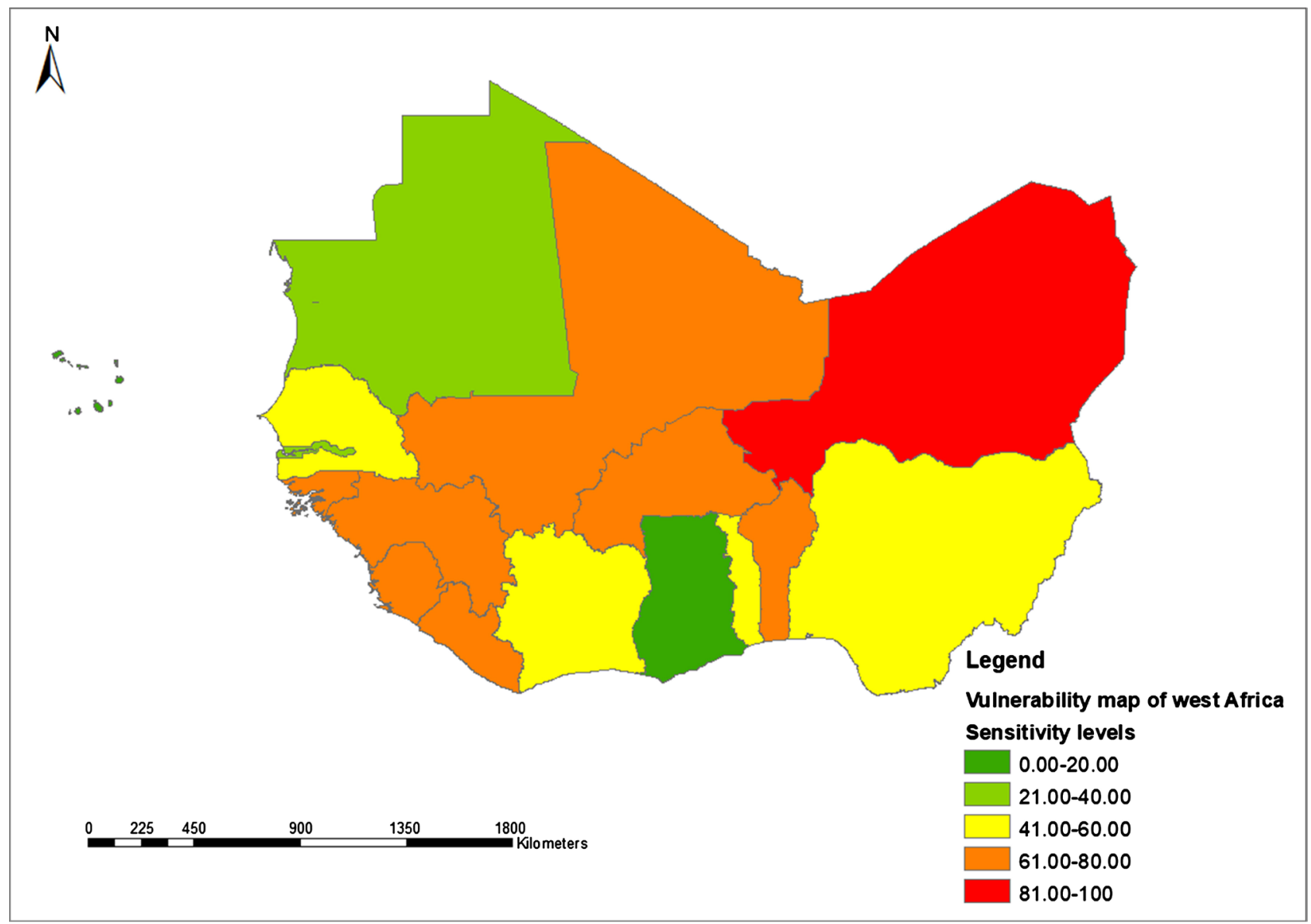

Figure 3. Map showing the levels of sensitivity of West African countries to climate change.

socioeconomic factors that can enhance or reduce vulnerability of a system or country to climate change and variability. Several studies have reported that socioeconomic factors must be considered when analysing vulnerability to climate change and its extremes (Antwi-Agyei et al., 2012; IPCC, 2014; Kamali et al., 2018). High incidence of poverty is a major contributing factor to vulnerability in many countries in West Africa (Acheampong et al., 2014). People living in these countries, especially farmers are confronted with various non-climatic shocks and stresses, which place additional burdens on their limited physical assets and constrain their ability to cope with the impacts of extreme climate events (Stringer et al., 2009). Low level of literacy by default means that rural people are excluded from decent paying jobs due to lack of adequate work skills and competence. In rural communities, lack of knowledge greatly limits ability of farmers to access information as well as new technology (Acheampong et al., 2014).

The vulnerability map presented in Figure 4 shows that Niger, Mali and Mauritania have the highest levels of vulnerability to climate change in West Africa. The countries with the least levels of vulnerability to climate change are Ghana, Cape Verde and Gambia. Generally, this study shows that most countries in West Africa are vulnerable to climate change with ten countries (Niger, Mauritania, Mali, Burkina-Faso, Liberia, Senegal, Guinea Bissau, Guinea, Benin and 


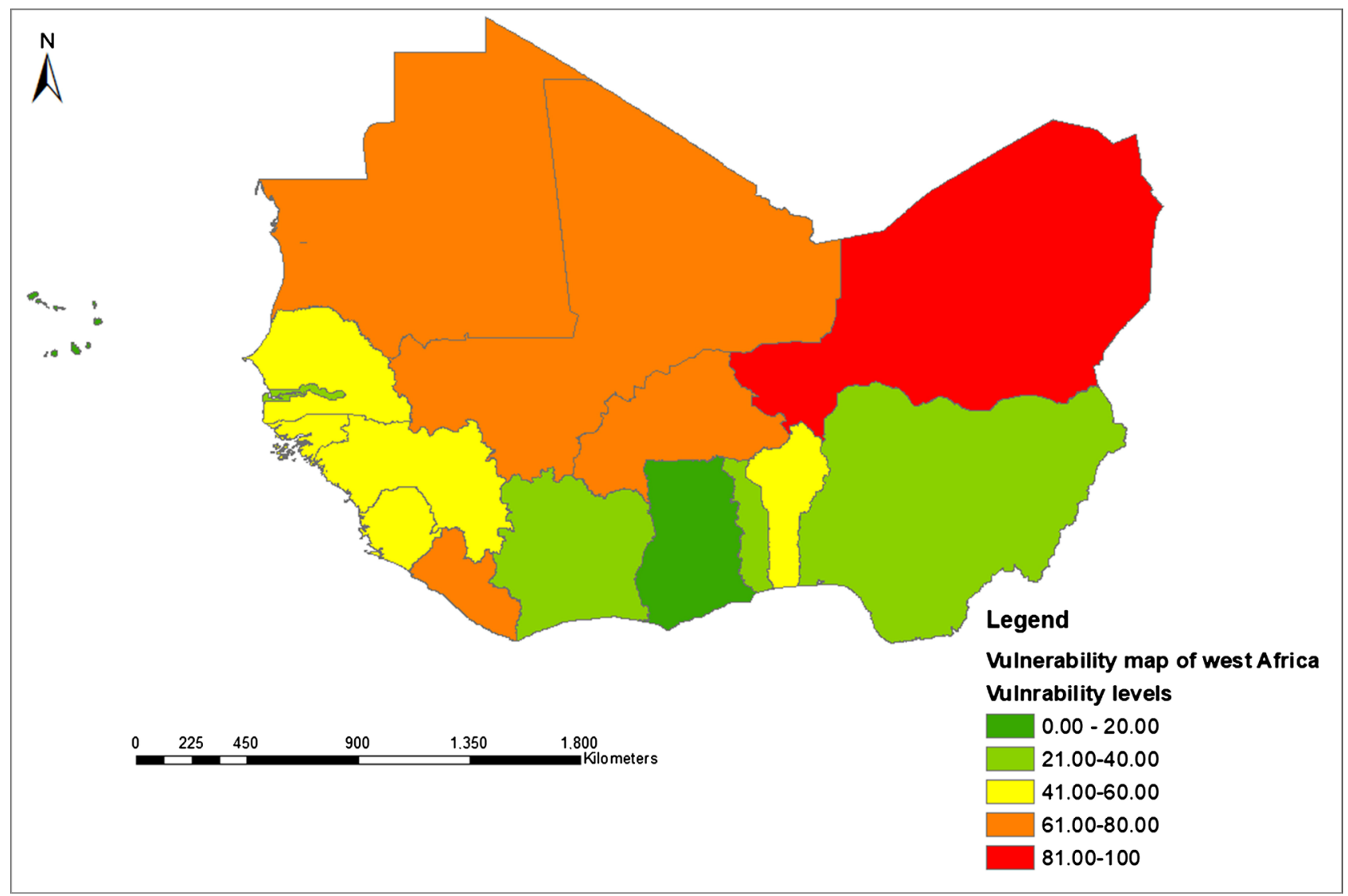

Figure 4. Map showing the level of vulnerability of West African countries to climate change.

Sierra Leone) having vulnerability levels higher than 50\%. This supports several previous researches (Muller et al., 2014; Mechler \& Bower, 2014; IPCC, 2014); that reported that West Africa is one of the most vulnerable regions to climate change and its extremes. Countries with vulnerability levels less than $50 \%$ in this study are Cape Verde, Ghana, Gambia, Togo, Ivory Coast and Nigeria. The vulnerability levels of countries in this study are strongly influenced by the exposure indicators which show the rainfall pattern in the region. The dry Sahel countries of West African with low amount of rainfall, sparse vegetation and mainly landlock are more vulnerable to climate change. Rainfed agriculture in these countries need to be supported with well planned irrigation system and other adaptation strategies such as drought resistance and early maturing seeds to reduce their vulnerability to climate change. This study also shows that coastal countries such as Liberia have high level of vulnerability to climate change. This can be attributed to low adaptive capacity to climate change and its extremes. Decades of civil unrest in such countries have disrupted their socioeconomic structure and affected their ability to cope with external natural shock like climate change and its extremes.

\section{Conclusion}

This study gives an overview of the vulnerability levels of countries to climate 
change in West Africa based on selected indicators. The study did not consider the internal variation in levels of exposure and adaptive capacity within each country. There is need for more detailed vulnerability analysis at the national and local levels to have better understanding of climate vulnerability within each country. Results of vulnerability mapping are influenced by available data and the choice of indicators. The choice of indicators used in this study is biased towards the agricultural sector.

The study concluded that the West African region is generally vulnerable to climate change and variability. The countries in the Sahel region, Niger, Mauritania and Mali are more exposed to climate change extremes, especially drought with limited adaptive capacity, making them the most vulnerable countries in the region. Effectively implementing policy strategies at the national and regional levels is critical towards addressing the long term impact of climate change and variability in the region. There is the need for well planned integrated adaptation measures to reduce the impact of climate change in the region. Measures such as improved agricultural practices, efficient irrigation and afforestation may enhance resilience of the agricultural sector to climate change and counterbalance the negative effects of drought on vegetation productivity in West Africa.

\section{Acknowledgements}

This work was funded by the West African Science Service Center for Climate change and Adapted Land Use (WASCAL).

\section{Conflicts of Interest}

The authors declare no conflicts of interest regarding the publication of this paper.

\section{References}

Acheampong, E. N., Ozor, N., \& Owusu, E. S. (2014). Vulnerability Assessment of Northern Ghana to Climate Variability. Climatic Change, 126, 31-44. https://doi.org/10.1007/s10584-014-1195-Z

Antwi-Agyei, P., Fraser, E. D. G., Dougill, A. J., Stringer, L. C., \& Simelton, E. (2012). Mapping the Vulnerability of Crop Production to Drought in Ghana Using Rainfall, Yield and Socioeconomic Data. Applied Geography, 32, 324-334. https://doi.org/10.1016/j.apgeog.2011.06.010

Asare-Kyei, D. (2017). Multiple Hazards Risk Profiling in West Africa: Assessment, Validation and Upscaling (p. 166). https://doi.org/10.1039/C7RA10870B

Bamba, A., Dieppois, B., Konaré, A., Pellarin, T., Balogun, A., Dessay, N., Diédhiou, A. et al. (2015). Bamba Changes in Vegetation and Rainfall over West Africa during the Last Three Decades (1981-2010). Atmospheric and Climate Sciences, 5, 367-379. https://doi.org/10.4236/acs.2015.54028

Blaikie, P., Cannon, T., Davis, I., \& Wisner, B. (1994). At Risk: Natural Hazards, People Vulnerability, and Disasters. London and New York: Routledge.

Bobadoye, A. O. (2016). Vulnerability Assessment of Maasai Pastoralist under Changing Climatic Conditions and Their Adaptation Strategies in Kajiado County. Ph.D. Thesis, 
Nairobi: Institute for Climate Change and Adaptation, University of Nairobi.

Brooks, N., Adger, W. N., \& Kelly, P. M. (2005). The Determinants of Vulnerability and Adaptive Capacity at the National Level and the Implications for Adaptation. Global Environmental Change, 15, 151-162. https://doi.org/10.1016/j.gloenvcha.2004.12.006

Chambers, R. (1989). Editorial Introduction: Vulnerability, Coping and Policy. Institute of Development Studies Bulletin, 20, 1-7. https://doi.org/10.1111/j.1759-5436.1989.mp20002001.x

Cutter, S. L., Boruff, B. J., \& Shirley, W. L. (2003). Social Vulnerability to Environmental Hazards. Social Science Quarterly, 84, 242-261. https://doi.org/10.1111/1540-6237.8402002

De Sherbinin, A., Chai-Onn, T., Jaiteh, M., Mara, V., Pistolesi, L., Schnarr, E., \& Trzaska, S. (2015). Data Integration for Climate Vulnerability Mapping in West Africa. ISPRS International Journal of Geo-Information, 4, 2561-2582. https://doi.org/10.3390/ijgi4042561

Downing, T. E. (1991). Assessing Socioeconomic Vulnerability to Famine: Frameworks, Concepts, and Applications. Research Report, Providence, RI: The Alan Shawn Feinstein World Hunger Program, Brown University, Providence.

Downing, T. E., \& Bakker, K. (2000). Drought Discourse and Vulnerability. In D. A. Wilhite (Ed.), Drought: A Global Assessment, Natural Hazards and Disasters Series (Chapter 45). New York: Routledge.

FAO (2013). Food Security and Agricultural Mitigation in Developing Countries: Options for Capturing Synergies. Rome: Food and Agricultural Organization.

Fiorillo, E., Maselli, F., Tarchiani, V., \& Vignaroli, P. (2018). Analysis of Land Degradation Processes on a Tiger Bush Plateau in South West Niger Using MODIS and LANDSAT TM/ETM+ Data. International Journal of Applied Earth Observation and Geoinformation, 62, 56-68. https://doi.org/10.1016/j.jag.2017.05.010

Gbetibouo, G. A., Ringler, C., \& Hassan, R. (2010). Vulnerability of the South African Farming Sector to Climate Change and Variability: An Indicator Approach. Natural Resources Forum, 34, 175-187. https://doi.org/10.1111/j.1477-8947.2010.01302.x

IPCC Intergovernmental Panel on Climate Change (2014). Climate Change: Impacts, Adaptation, and Vulnerability. Working Group II Contribution to the IPCC 5th Assessment Report. https://doi.org/10.1017/CBO9781107415416

Kamali, B., Abbaspour, K. C., Wehrli, B., \& Yang, H. (2018). Drought Vulnerability Assessment of Maize in Sub-Saharan Africa: Insights from Physical and Social Perspectives. Global and Planetary Change, 162, 266-274. https://doi.org/10.1016/j.gloplacha.2018.01.011

Lebel, T., \& Amani, A. (1999). Rainfall Estimation in the Sahel: What Is the Ground Truth? Journal of Applied Meteorology and Climatology, 38, 555-568. https://doi.org/10.1175/1520-0450(1999)038<0555:REITSW >2.0.CO;2

Mechler, R., \& Bouwer, L. M. (2014). Understanding Trends and Projections of Disaster Losses and Climate Change: Is Vulnerability the Missing Link? Climatic Change, 133, 23-35. https://doi.org/10.1007/s10584-014-1141-0

Midgley, S. J. E., Davies, R. A. G., \& Chesterman, S. (2008). Climate Risk and Vulnerability Mapping in Southern Africa: Status Quo (2008) and Future (2050). Cape Town: One World Sustainable Investments.

Mortimore, M. J., \& Adams, W. M. (2001). Farmer Adaptation, Change and "Crisis" in the Sahel. Global Environmental Change, 11, 49-57.

https://doi.org/10.1016/S0959-3780(00)00044-3 
Muller, C., Waha, K., Bondeau, A., \& Heinke, J. (2014). Hotspots of Climate Change Impacts in Sub-Saharan Africa and Implications for Adaptation and Development. Global Change Biology, 20, 2505-2517. https://doi.org/10.1111/gcb.12586

O’Brien, K., Leichenko, R., Kelkar, U., Venema, H., Aandahl, G., Tompkins, H., Javed, A., Bhadwal, S., Barg, S., Nygaard, L., \& West, J. (2004). Mapping Vulnerability to Multiple Stressors: Climate Change and Globalization in India. Global Environmental Change, 14, 303-313. https://doi.org/10.1016/j.gloenvcha.2004.01.001

Rockstrom, J. (2008). Water Resources Management in Smallholder Farms in Eastern and Southern Africa, an Overview. Physics and Chemistry of the Earth Part B-Hydrology Ocean and Atmosphere, 25, 275-283. https://doi.org/10.1016/S1464-1909(00)00015-0

Stringer, L., Dyer, J., Reed, M. S., Dougill, A. J., Twyman, C., \& Mkwambisi, D. (2009). Adaptations to Climate Change, Drought and Desertification: Insights to Enhance Policy in Southern Africa. Environmental Science and Policy, 12, 748-765.

https://doi.org/10.1016/j.envsci.2009.04.002

Turco, M., Palazzi1, E., von Hardenberg, J., \& Provenzale, A. (2015). Observed Climate Change Hotspots. Geophysical Research Letters, 42, 3521-3528.

https://doi.org/10.1002/2015GL063891 